\title{
Ranting in 2020: Reflecting About the Past and the Future (with Concerns About the Present)
}

\author{
Irl B. Hirsch, MD \\ "Computers and the internet have made it really easy to rant. \\ It's made everyone overly opinionated."-Scott Weiland
}

Are all of us "overly opinionated"? As I write my 7th annual rant, that has certainly been a primary concern. Originally, my whining was simply a venue for me to vent. Now it appears I am not the only health care provider feeling the pain of our dysfunctional system. The history of this rant is that 7 years ago, during a nonentertaining New Year's Day Rose Bowl game, I decided to write about my last day in clinic for that year. We all have days that are more frustrating than others, but what I realized is that every day seemed to be like my last day. Seeing patients remains a joy-it is the punishment of working in a dysfunctional system that is the challenge. So, is it possible to change the system?

"If presidents can't do it to their wives, they do it to their country."-Mel Brooks

I will not pretend to be a political writer, and no one person is responsible for our system of health care in this country. But the mentioned quote is where we are with affordable access to health care and there is a political component of this that is not well appreciated. I happened to learn about a fascinating website called "opensecrets.org" that is the portal for the Center for Responsive Politics. ${ }^{1}$ The organization describes itself as "nonpartisan, independent and nonprofit...the nation's premier research group tracking money in U.S. politics and its effect on elections and public policy."

I took one political science class when I was a freshman in college (for the record, it was during that class that Jimmy Carter beat Gerald Ford) so I know little about political lobbying. But what I do know is that from reading Opensecrets (and not surprisingly) is that pharmaceutical companies have been the biggest political spenders for years. ${ }^{2}$ This is a bipartisan fundraiser, with Republicans receiving 64\% of industry contributions since the 1990 election cycle. To put this in perspective, between the 1990 election cycle and now, the National Rifle Association has spent \$23 million in "contributions" and $\$ 55.3$ million in lobbying. For that same time period, total contributions to pharmaceutical manufacturing are \$207.4 million. ${ }^{3}$ This number does not include medical devices and supplies, nutrition and dietary supplements, and others.
Of even greater interest to me is that for the 2019-2020 cycle (as of December 2019), 2 of the top 10 contributors are insulin manufacturers and the third insulin company is number 13. What is even more interesting is the top recipient of funding for this election cycle is a well-known senator from the state of Kentucky (who happens to be in the news quite a bit these days). I think about this a lot, especially when I complete all of my dualities and conflicts of interest for continuing medical education, my research projects, and my writing (including this rant!).

Although I need to state my dualities before even speaking to a medical student and need to confirm my Sunshine Act Open Payments is correct (so my institution will not terminate my employment), it still surprises me that our politicians from both sides of the aisle are not required to state their conflicts-of-interest, whereas physicians need to wear them on their backs. After spending time on opensecrets.org, I have concluded that the only reason why politicians do not state their dualities is there are simply too many as it would require too much time. If they did state all of their conflicts, we would never hear any substance, which come to think of it, is consistent with the comment by a famous American author:

"Suppose you were an idiot, and suppose you were a member of Congress; but I repeat myself."-Mark Twain

For me the most frustrating aspect of clinical care continues to be the administrative challenges for our Medicare beneficiaries. I am particularly sympathetic for this group, as $>80 \%$ of my patients have type 1 diabetes and a third of them are $>65$ years old. Although I could rant about numerous bureaucratic challenges for the diabetologist caring for this population, the most important comment is the fact that various distributors for durable medical equipment all interpret the rules differently. This is true for both blood glucose test strips and continuous glucose monitoring (CGM) sensors.

I have noted the problems of this part of the system in the past, but this year resulted in a new low even for Centers for Medicare and Medicaid Services (CMS). I have a patient who participated in our study WISDM (Wireless Innovation for Seniors with Diabetes Mellitus) where he was using a Dexcom CGM and had access to all of the test strips he

Department of Medicine, University of Washington School of Medicine, Seattle, Washington. 
needed. After the study, he decided to wait for Medicare to cover the Dexcom Gen 6 understanding he would only be able to use fingerstick glucose testing until the newer sensor was available (which was in October 2019). Even before the study, he typically used 8 to 10 glucose strips per day. He has had multiple episodes of severe hypoglycemia and this frequency of glucose measurements allowed him to safely manage his diabetes.

The problem was, after the study, he had a new distributor and they were going to have nothing to do with 8 strips per day, let alone 10. Numerous letters and changes to the note were provided (as demanded by this very for-profit distributor). I realized besides the incentive of a Medicare audit, they also had a financial incentive to withhold strips. My only goal was to keep my patient as safe as possible. Four times I was asked to change and addend the note to clarify why he needed so many strips. Four times I obeyed the distributor police.

The last demand was that I write how long he would require such a high strip burden. I do hope at least someone read and even smiled at what was written in his chart note. This epic note (no pun intended) explained, in layman terms, the history of glucose monitoring going back to urine glucose tasting testing in 1500 BC to Karl Trommer's clinical urine glucose test in 1841 using an acid hydrolysis method. ${ }^{4}$ Eventually the reader would learn about the CliniTest glucose monitoring at home (I decided to spare the reader about the single vs. double-voided urine collection controversy). Eventually, the reader learned about home blood glucose monitoring and CGM.

Although this passive aggressive response to this distributor was accurate, I doubt the reader found the historical explanation of any importance only because at this patient's next visit 3 months later I was again asked to defend his blood glucose strip frequency. Sigh.

"I may be drunk, Miss, but in the morning, I will be sober and you will still be ugly."-Winston Churchill

Perceptions are always in the mind of the beholder, but today every aspect of a physician's life is based on evaluations. In academia, there are more evaluations from students, residents, and fellows, but all of us who see patients are now dependent on patient evaluations that come in all forms. As patients, all of us receive evaluations of our overall experience, including of course a detailed survey about the physician. For many practices, satisfaction surveys are a critical aspect of job performance and an important part of the equation for financial incentives.

There are other frequent venues to evaluate physicians, particularly on the Internet. I was not even aware of physician evaluations on Yelp until I was emailed that I received a low grade ( 1 star out of 5) from a dissatisfied patient. I went to the site and indeed, I was a horrible disrespectful man, saying derogatory things about a woman's weight. Not only that, I had horrible body odor (at least no mention was made of my bad breath). In the email I received, I was told the poor review could be removed from the website for $\$ 3000$. After checking with a few people, I learned this is a common scam and many of these evaluations are posted by swindlers looking to make a quick dollar. Disinformation on-line is not new, and I cannot blame this on Vladimir Putin as he is not my patient (I do not think mentioning this is a HIPPA violation but if he had been my patient, we would provide him with a Russian translator and he could e-care me his blood sugars in any language he prefers).

\section{"Some guy hit my fender, and I told him 'be fruitful \\ and multiply' but not in those words."-Woody Allen}

There are times I get so frustrated I am not sure if I should laugh or cry. This last example comes to mind as it happened near the end of 2019. I received a hospital discharge summary from an outside hospital where a patient of mine with type 1 diabetes was admitted for intravenous antibiotics for sepsis. The patient has little to no family support and was cognitively impaired from her illness. I knew the story would have a bad ending when I saw on the discharge summary diagnosis \#3: "IDDM." For younger readers, this is the abbreviation for "insulin-dependent diabetes mellitus," nomenclature that departed our nomenclature 23 years ago. ${ }^{5}$ My worst fears were confirmed when reading the discharge note that her glargine was withheld, "sliding scale insulin" was instituted (with insulin lispro), and within a day she was transferred to the intensive care unit for diabetic ketoacidosis.

The good news is she survived (a low bar), but I do have to wonder how common this is in hospitals where there is little expertise in type 1 diabetes? In the nonacademic hospitals, it is now rare for endocrinologists to see patients (I routinely receive phone consults from physicians in my state as there are no endocrinologists on staff at most hospitals). We know endocrinology fellowships are less competitive and attractive than in years past, ${ }^{6}$ and it is clear to me that some hospitalists have minimal experience in the management of type 1 diabetes. How common will my patient's scenario be 10 years from now?

Currently, it is family advocacy that is the primary protector for patient safety when admitted to certain hospitals for type 1 diabetes. We all have our personal stories, but why is this still the case as we enter 2020 ? Will this change by 2030 ? And if I am still ranting by 2030, will I still be fighting the use of sliding scale insulin? ${ }^{7}$

\section{"If you think in terms of a year, plant a seed; if in terms of ten years, plant trees; if in terms of 100 years, teach the people."-Confucius}

Our goal should be teaching people, but, most of us are planting trees. My hope was that by 2020, finding topics for ranting would become more difficult. In fact, only lack of space precludes me from addressing ridiculous stories, such as trying to obtain mifepristone for Cushing's disease in a woman with type 1 diabetes, or obtaining every 2 -year cpeptide levels (which were all unmeasurable) to prove to a distributor of CMS for insulin pump therapy that a patient really did have type 1 diabetes and she was not cured. And who could forget the anesthesiologist who called me wanting to know how much intravenous glargine to give for a patient before surgery? And finally, there is the 82-yearold woman with type 2 diabetes who had coronary artery bypass surgery in the past where the naturopath stopped the statin to start liothyronine to improve low density lipoprotein particle size (she did not have hypothyroidism).

We all have these stories, but I want to thank Dr. Satish Garg for giving me the platform to share some of them with you. Let us hope next year there actually will be less need to rant. 


\section{References}

1. Our vision and mission: inform, empower, and advocate. https://www.opensecrets.org/about/ (accessed December 21, 2019).

2. Pharmaceutical manufacturing-summary. https://www.opensecrets .org/industries/indus.php?cycle $=2020 \&$ ind $=$ H4300 (accessed December 21, 2019).

3. Pharmaceutical manufacturing-totals. https://www.opensecrets .org/industries/totals.php?cycle $=2020 \&$ ind $=\mathrm{H} 4300$ (accessed December 21, 2019).

4. The evolution of diabetes testing: from taste to test. https:// www.sekisuidiagnostics.com/blog/diagnostics/2017/12/16/ evolution-diabetes-testing-taste-test/ (accessed December 21, 2019).

5. The Expert Committee on the Diagnosis and Classification of Diabetes Mellitus: Report of the Expert Committee on the Diagnosis and Classification of Diabetes Mellitus. Diabetes Care 1997;20:1183-1197.

6. Fellowship match data and reports. www.nrmp.org/fellowshipmatch-data/ (accessed December 21, 2019).

7. Hirsch IB: Sliding scale insulin: time to stop sliding. JAMA 2009;14:213-214.

Address correspondence to:

Irl B. Hirsch, MD

Department of Medicine

University of Washington School of Medicine

750 Republican Street

Building F, 3rd Floor

Seattle, WA 98109

E-mail: ihirsch@uw.edu 